\title{
Night Market Cultural Transformation and Upgrading
}

\author{
Runzhe Li, Xiujuan Wang*, Yi Wang \\ School of Public Administration, Shandong Agricultural University, Tai'an, China \\ Email: *xjw9007@126.com, wangyi7224513@126.com
}

How to cite this paper: Li, R. Z., Wang, X. J., \& Wang, Y. (2021). Night Market Cultural Transformation and Upgrading. Journal of Service Science and Management, 14, 412-428. https://doi.org/10.4236/jssm.2021.144026

Received: April 27, 2021

Accepted: July 27, 2021

Published: July 30, 2021

Copyright ( 2021 by author(s) and Scientific Research Publishing Inc. This work is licensed under the Creative Commons Attribution International License (CC BY 4.0).

http://creativecommons.org/licenses/by/4.0/ (c) (i) Open Access

\begin{abstract}
Night market is an important economic model in the city. The success of the night market development is of great significance to the city management and development. This paper analyzes the current situation of Taishan night market and the organization management method. Based on the comparative analysis with Chengdu, we put forward suggestions for the transformation of Taishan night market from strengthening the night market network management, solving the problem of infrastructure, construction of network information platform, innovating management mode, creating intensive cultural management characteristics, combining cultural development with "sharing" economic concept, thus creating greater benefits.
\end{abstract}

\section{Keywords}

Night Market, Cultural Transformation, Upgrading

\section{Introduction}

The night market is an important economic model in cities (Table 1). Taking the National Day period in 2020 as an example, the night economy accounted for a very high share (Figure 1). The success of night market development is of great significance to the management and development of the city. According to the statistics of night market keywords research, the volume curve of published articles of the night market is roughly S-shaped, the attention of the night market research is increasing year by year, and the study of the night market has been developing to a further depth, which has enough research value. From the point of view of residents, the night market is a place for residents to relax, and it improves the quality of life of residents because of its characteristics of low price and rich variety. The research of the night market can offer more broad facilities for residents' lives (Liu, Chou, \& Lin, 2021); from the value of tourism, night 
Table 1. Top 10 cities in the nation's supper trading volume.

\begin{tabular}{ccc}
\hline \multicolumn{3}{c}{ Top $\mathbf{1 0}$ cities in the nation's supper trading volume } \\
\hline Consumption ranking & Cities & Proportion of the whole day's transaction volume (\%) \\
\hline 1 & Shanghai & $12.2 \%$ \\
2 & Hangzhou & $11.1 \%$ \\
3 & Shenzhen & $15.5 \%$ \\
4 & Beijing & $9.8 \%$ \\
5 & Wenzhou & $15.6 \%$ \\
6 & Guangzhou & $12.2 \%$ \\
7 & Wuhan & $9.6 \%$ \\
8 & Xiamen & $15.5 \%$ \\
9 & Fuzhou & $14.0 \%$ \\
10 & Nanjing & $11.2 \%$ \\
\hline
\end{tabular}

*Source: 2021-2027 China's night economic industry market competition status and development trend analysis report, ZhiYan.org.

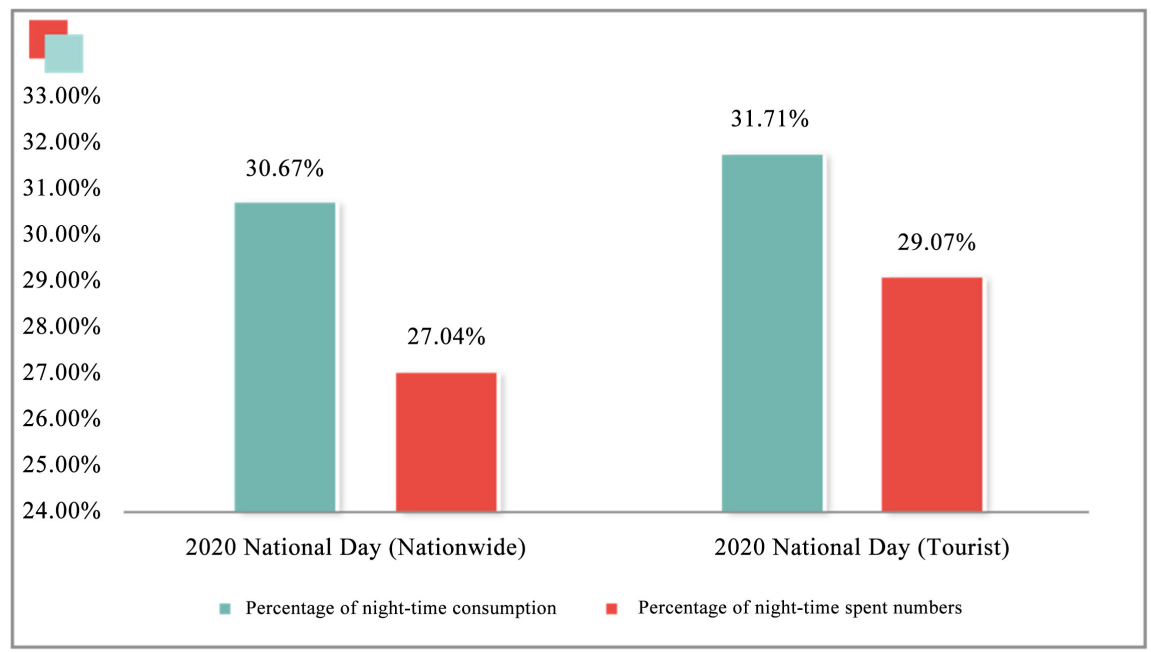

Figure 1. Proportion of domestic night consumption during National Day 2020. Percentage of night-time consumption $=$ Total night consumption/Total daily consumption; Source: 2020 China Night Economic Development Report, China Tourism Research Institute and UnionPay Business Big Data Joint Laboratory.

market-as a business card of the city, often attracts a large number of tourists to visit, and brings great economic benefits. This research can promote the construction and role play of night markets; for the society, most of the mobile vendors in the night market take the laid-off workers and the unemployed as the main body. Life is tougher for these sellers. The existence of the night market gives them employment opportunities with more flexibility and low entry barriers, ensures their basic living needs, alleviates employment pressure, and provides an open and competitive employment environment, encourages entrepreneurship and would create a good social atmosphere. From each level, it has its 
important existence and research value (Liu, Chou, \& Lin, 2021). The research significance of this topic lies in the hope of understanding the current development of Taishan Night Market through the article, to find out the current problems, and through strengthening construction, cultural transformation, sharing economy and other ways to reform, so as to make the night market get a better development, and promote the economic development of the city and increase the attractiveness of the city. The limitation of this paper lies in that although the current development situation of Taishan Night Market has been carefully understood and the transformation methods have been elaborated. Detailed method guidance is still needed for each department involved in the transformation of the night market in the future research, so as to promote the comprehensive development.

The article is organized as follows. The first part summarizes the basic information of the night market. The second part elaborates the significance of studying the night market. The third part describes the current situation of Taishan Night Market. The fourth part explains in detail the organizational form and management mode of Taishan Night Market. This part includes the official organization method, the market organization method and the non-governmental organization method. The fifth part analyzes the cultural transformation of Taishan Night Market. The sixth part of the Taishan Night Market cultural transformation to achieve the way to carry on the assumption. The transformation method mainly includes four aspects: strengthening management and infrastructure construction, establishing information network information platform and innovating management mode, combining Taishan culture to carry out intensive development, and promoting sharing economy. The seventh part tells about the livelihood benefits of Taishan Night Market.

But at present, the domestic research on the night market is mainly focused on the environment, hygiene and other aspects, and according to the analysis of the research site, the study subjects are also concentrated in Beijing, Taiwan and other cities with strong comprehensive strength, the attention to Tai'an and other prefecture-level cities is low, the existing problems cannot be well developed and rectified. Therefore, the study of the night market still needs to be strengthened.

\section{Research Value of Taishan Night Market}

The study of Taishan Night Market has great significance at all levels.

From the perspective of social value, Taishan Night Market vendors take the laid-off workers, the unemployed and people living in difficulties as the main body, the existence of the night market solves the basic living problems for these people, moreover, it helps the government to ease the pressure of relief. In addition, the night market can encourage the "grassroots" to start their own businesses, enhance the driving force of urban development, and further possess the urban spirit of openness and competition. Studying the problems of the night 
market and proposing corresponding countermeasures will better promote social development.

From the perspective of life value, the existence of Taishan Night Market provides a place for residents to leisure and entertainment, which exerts great influence on relieving the pressure of work and improving the quality of life of urban residents. In addition, cheap goods in night markets are attractive to the low-income groups in the city, providing a place for them to shopping (Li, Kong, \& Yang, 2021). Through the investigation of the current situation to reconstruct the night market, it will provide more convenience for residents' lives with the construction of a good shopping and consumption environment.

From the perspective of tourism value, Taishan Night Market is the business card of a tourist city, the main weapon to attract tourists, and the benchmark of the degree of a city's development. The existence of night markets plays an important role in the development of urban tourism. Researching on the night market and creating a good city business card, will further promote the development of urban tourism.

From the perspective of application value, this paper conducts research on urban planning, facility construction, operation management and other levels, and proposes systematic implementation strategies to optimize spatial layout and resource allocation, so as to carry forward the urban night economic benefits and perpetuate the urban context. It has important application value for integrating urban space and realizing the organic combination of economic, social and ecological benefits (Villaseca, 2021).

\section{Status of Taishan Night Market}

The night market is an economic activity that occurs at night and is one of the most important carriers of the night economy. In recent years, with the gradual acceleration of the pace of life, the night market has become an important place for leisure and entertainment of some residents in the face of people's greater survival pressure and increasing material and cultural needs. However, in the face of new development opportunities, traditional night markets also have the problems such as single service varieties, lack of characteristics to attract consumers, poor hygiene conditions, and occupation of roads that obstruct the traffic. As a business card to show the level of urban economic development and openness, the night market needs more reform and transformation in the transition period of society.

Taishan Night Market in Tai'an City also has such problems. Taishan Night Market was founded in 1986 and has a history of more than 30 years. In the course of decades of development, other night markets or gathering stalls in Tai'an have gradually been banned as the city develops. Taishan Night Market continues to this day because it is located in the bustling city center at the foot of Mount Tai, surrounded by densely populated residential areas, located at the intersection of three roads, and convenient transportation, it has become the most representative night market in Tai'an. At the same time, the label of the tourist 
city and the resident population of 5.5 million have also brought a steady stream of tourists to the Taishan Night Market, but the overall development level of Tai'an night markets is still at a relatively low stage.

According to the investigation, there are more than 200 stalls in Taishan Night Market, most of which are engaged in the food processing industry (Table 2). A large number of snacks and barbecue stalls gather here, accounting for about $60 \%$ of the total number of stalls (Figure 2). From the beginning to the end of the street, most of them are catering businesses like barbecue, cold drinks and other snacks. Most of these snacks need to be processed on the spot, and are accompanied by various noise, garbage, oil fume, which seriously affect the normal life of surrounding residents. At the same time, some vendors directly back to the trash can for food processing, food processing mainly fried or barbecued, which is difficult to consider the safety of oil, some stalls have not changed the boiling oil within a few hours of operation. Most of these food processing night market vendors do not have the health certificates of the practitioners, the certificates of qualified food purchasers, or even the production hygiene licenses, therefore the food hygiene cannot be guaranteed. It is difficult to guarantee the quality of raw materials and sanitary conditions of food.

Table 2. Statistical chart of commodity type.

\begin{tabular}{cccc}
\hline Commodity types & Number of stalls (units) & Commodity types & Number of stalls (units) \\
\hline Cold drinks & 9 & Toys & 4 \\
Snacks & 53 & Entertainment & 4 \\
Fruit & 9 & Craft Category & 19 \\
Jewelry & 19 & Clothing Shoes and Hats & 52 \\
Package Class & 4 & Mobile Phone Stickers & 5 \\
Barbecue & 15 & Flower Plants & 2 \\
Pet & 3 & Tourism Specialty & 4 \\
Books & 6 & Articles for Daily & 18
\end{tabular}

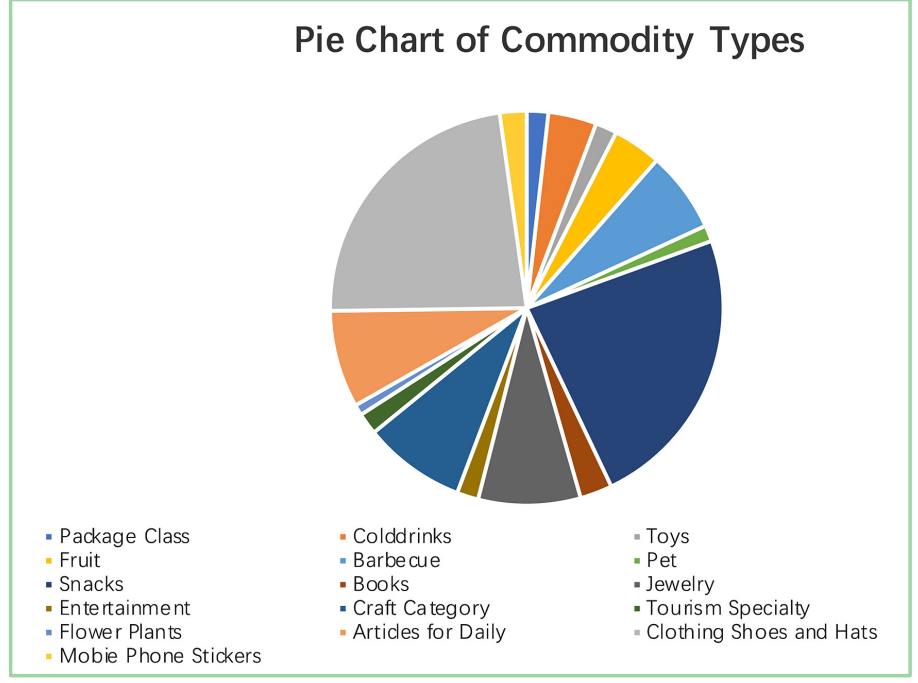

Figure 2. Pie chart of commodity types. 
The rest of the stalls mainly serve for low-priced clothing, shoes, bags, and electronic digital products. Taishan Night Market, with snacks, clothing and simple entertainment as its main components, has low commodity prices and low consumption levels. It is a place that can only meet the low-end shopping needs of local residents and the dietary needs of tourists, so it is difficult to effectively drive the rapid development of economy and society.

For tourists from other places, Taishan Night Market lacks sufficient appeal. Most of the tourists come to Tai'an, hoping to see Mount Tai, learn about Tai'an culture, feel local customs and taste local food. This is also the great advantage of Tai'an in the development of tourism. However, considering the development of Tai'an night market stalls, most of the stalls sell barbecue and other foods, which are too catering to the dietary needs of consumers, and do not meet the original intention of the night market and the current development needs.

As for the stalls that can really meet the cultural needs of tourists, the proportion of them in the night market can be said to be very small. According to the investigation, there are only four stalls involving Tai'an culture. Taishan culture has not been paid attention to and propagated, and the cultural value of the night market can hardly be reflected in practice (Jiang, Kellard, \& Liu, 2020). The cultural construction of the night market is neglected, making it lack sufficient cultural accumulation, Taishan culture cannot be well publicized and carried forward, the potential of development is small, and it cannot meet the needs of tourists. In the case that the night market is unable to bring unique services to outside tourists, it is naturally difficult to expand the scale and better transform and develop.

Generally speaking, most people visit the night market with a leisurely shopping mentality, especially for snacks. Young consumer groups expressed that they don't want snacks to be completely banned, so managers should refer to consumers' opinions and gradually adopt improvement measures, rather than a one-time compulsory ban. Most consumers are less satisfied with the overall situation of the night market, in terms of the environment, the hygiene situation of the night market is unsatisfactory, many consumers have poor awareness of environmental protection, they wantonly throw away garbage and make the cleaning process of sanitation workers time-consuming and laborious; in terms of traffic, the night market is not only a commercial street, but also a gathering area of residential quarters and school districts where has a large flow of people, many vehicles and traffic congestion which leads the dissatisfaction of the consumers; In terms of food hygiene, the vast majority of consumers do not understand this, and they have poor awareness of food safety, which poses a greater potential health hazard; In terms of economy and culture, night markets are dominated by clothing, snacks and entertainment, with low commodity prices and low consumption levels, which cannot effectively promote the rapid development of the economy. At the same time, most of the night markets are close to the school districts, and most of the living groups are the old and students. The noise is disturbed at night, which seriously affects their normal work and rest. 
When consumers stop to select goods, they often gather on the side of the road and discard the packaging of the goods at will. Night markets often run until midnight, diners drink and punch, rowdy fights and may defecate indiscriminately.

Based on these conditions, the transformation of Taishan Night Market is not only expected, but also imminent.

\section{Organization and Management of Taishan Night Market}

In order to realize the transformation of Taishan Night Market, we must first solve the problems of Taishan Night Market, clarify the organization and management methods, and control the night market in a targeted manner.

According to the investigation and research, the organization and management methods of Taishan Night Market can be roughly divided into three categories. The first is the "Official Methods of Organizing Night Markets" for government intervention in management, the second is the "Market Methods of Organizing Night Markets" coordinated by the Market Management Office, and the third category is the "Non-governmental Methods of Organizing Night Markets" spontaneously formed by night market vendors and other operators. The three types of organization and management measures are implemented in parallel to jointly maintain the operation of the night market.

\subsection{The Official Methods of Organizing Night Markets}

As early as 2007, the People's Government of Tai'an Municipality issued a notice on further strengthening the comprehensive tax management of the society, in order to ensure that the national tax receivables are fully collected, and to fully mobilize the enthusiasm of all aspects of tax assistance and protection. In 2010, the night economy began to appear, the night economic development has not formed any characteristic, the food safety management of catering stalls has always been a difficult and focal issue. In 2011, law enforcement officers guided and regulated all catering stalls in the night market, registered the stalls, and issued the "Tai' an Catering Service Food Procurement Requesting Ticket Ledger", The "Official Methods of Organizing Night Markets"- guided from the macro level of urban development, strives for food hygiene, clean environment, perfect infrastructure while satisfying the normal traffic and leisure of the night market, but the effect is a problem to be studied.

\subsection{The Market Methods of Organizing Night Markets}

As an "invisible hand", the market plays a great role in the economic field and assists the smooth progress of government regulations. Therefore, Taishan Night Market has set up a market management office, which is responsible for its daily management and maintenance. The management office issues the daily notices and stipulates according to the requirements of market standards that all booths shall be operated on the stage and the operation shall be certified; according to 
food hygiene standards and requirements, food business operators are required to have three prevention measures and hang health certificates. The "Market Methods of Organizing Night Markets" is a kind of management measure formed in accordance with the actual situation in order to meet the requirements of relevant government departments. It aims to assist the healthy operation of night markets, strive to meet relevant health and safety standards, and ensure the basic rights and interests of vendors and consumers.

\subsection{The Non-Governmental Methods of Organizing Night Markets}

As the main body of night market activities, vendors are active "cells" of the market. With the development of economic activities in Taishan Night Market, vendors have spontaneously formed a series of regulations, mainly relying on their conscious compliance. The "Non-governmental Methods of Organizing Night Markets" is a kind of habitual system which is formed spontaneously by night market vendors without explicitly stipulated. It has played an important role in the formation of a more standardized and orderly night market environment.

\section{Cultural Transformation Analysis of Taishan Night Market}

In dealing with the development of night markets, the government management methods, economic development levels, and public awareness of the masses are different in each city, which lead to the different development levels and speeds of night markets. For the northern region with traditional consumption concepts and thinking habits, the rise and development of night market is obviously slower than that of the southern region. For example, night markets such as Jinli Night Market in Chengdu and Shangxiajiu Pedestrian Street in Guangzhou have become "business cards" of characteristic cities that attract local citizens and outside tourists.

But now most of the night markets are gradually disappearing and banned, The Honglou Night Market in Jinan, the capital city near Tai'an, has a history of more than ten years. However, the existence and development of Honglou Night Market have conflicts with the city appearance and urban management, such as traffic congestion, insufficient supporting facilities, worrisome sanitary environment, multiple management agencies, and prominent neighborhood conflicts. As a result, with the improvement of Jinan's urban construction level, the renovation of the appearance of the city and the struggle for the title of sanitary city, many once prosperous night markets have gradually disappeared or been banned.

Nowadays, in order to develop the night economy and promote urban development, major cities have begun to build night markets. Shanghai, Xiamen and Xiamen plan to build "landmark-type" night markets to expand consumption, prosper the market, tap potential consumption, attract foreign consumption and 
cultivate new consumption hot spots, and enhance the driving effect of consumption on economic growth. How to find a joint point that not only maintains the image of the city, but also promotes the development of the city's night economic night market, properly handles the contradiction between urban management and development, and makes the stall market a bright spot of the economy and a "business card" of the city poses a difficult problem for the government and various departments.

As one of the famous tourist cities in China, Tai'an attracts a large number of tourists every year because of its cultural characteristics. Therefore, Tai'an can use this as a starting point to learn from other cities that use local characteristics to set up night markets to stimulate the vitality of Tai'an night markets.

As the core of Tai' an tourism, Mount Tai is a household name in China. It has a long history and rich cultural connotations, making it an important historical and cultural city in Shandong. Taking the National Day military parade as an example, at the 60th anniversary celebration of National Day, the float representing Shandong was named "Daiqinghailan (Mount Tai is lush, the ocean is blue)"; at the 70th anniversary of the military parade, the float representing Shandong was named "Guotaimin'an (peace and prosperity)" with Mount Tai as its main image, indicating that the country is prosperous and the people are at peace and the permanence of the landscape. It can be said that the significance of Mount Tai to China is not only a tourist attraction, but also an important image of politics and traditional culture, a symbol of Tai'an and a symbol of the country. Because of its importance, Tai'an attracts more than 10 million tourists every year. In 2018, the number of tourists reached 75,894,300. The number of tourists and tourism income have achieved double growth and increased year by year. Tourism with Mount Tai as the core has become the main industry in Tai'an. This also provides a sufficient audience for the development of the night market. Therefore, the transformation of Taishan Night Market can take advantage of its historical advantages and take culture as the main direction of transformation.

There are many cities with historical and cultural backgrounds similar to Tai'an in China. In some tourist cities with strong history or characteristics, managers have integrated unique cultural products and activities into the construction of night markets, which has got very good benefits. Taking Taiwan as an example, there are many night markets with the long history of development, complete types of services and distinctive features. The famous Taipei Shilin Night Market, which is famous for its rich Taiwanese cuisine, is a special food shrine for the domestic and foreign. At the same time, the local night market also sells a large number of handicrafts with local characteristics, such as souvenirs featuring some scenic spots and handicrafts related to local celebrities, as well as the display of local cultural heritage. These rich products not only give tourists the opportunity to buy souvenirs, but also let them deepen their understanding of local customs. Fengshan China Street Night Market, as a famous sightseeing night market, has many scenic spots and historic sites, so that visitors can feel humanistic feelings during the night tour, while Huaxi Street Night Market is 
well known for being the scenic spot of Taiwanese famous film Jiameng ... Although many night markets belong to the same economic type, they all rely on the local characteristics of Taiwan to find a suitable way of development. The style of each night market is unique and very representative. These night markets not only let us see the local customs of Taiwan, but also bring huge economic benefits, in 2008 alone, it contributed the revenue of $\mathrm{T} \$ 508.1$ billion to Taiwan, making it a golden sign for tourists in the tourist city.

There is also a precedent for the development of the wide and narrow alley night market in Chengdu, a major town in the southwest. As a famous scenic spot in Chengdu, it also realizes the function of night market in addition to daytime viewing because of the rich characteristics of local night life. Here is a good model for the development of night life through history and culture, and there is a unique night market development law with "humanistic accumulation" as the core development power. On the basis of preserving the original appearance of historical buildings and ancient walls, the wide and narrow alleys have also increased the design and management of urban lighting, forming a model of "business circles, scenic spots and lights" to enhance landscape creation; At the same time, the addition of performing arts projects and intangible cultural heritage, efforts to "resurrect" traditional skills, so that the cultural projects like drama, ear picking, face-changing which old Chengdu people proud of have been "resurrected" in the narrow alleys after experiencing the dilemma of no one developing and falling for a short time. This development strategy not only protects the heritage of culture, but also caters to the living habits of local residents and the needs of tourists, and greatly stimulates domestic demand. At the same time, as a gathering place for mobile vendors, it also provides a large number of employment opportunities and solves the survival problems of some people. It can be said to kill many birds with one stone.

Similar to these, there are Beijing Big Fence, Xiamen Dianqian Night Market, Qingdao Taidong Night Market and so on. Only combined with local characteristics, can it is possible to be unique, rather than the same with other night markets, lacks of distinctive style.

\section{How to Realize the Cultural Transformation of Taishan Night Market}

Based on the above comparative analysis with Chengdu, we suggest the transformation of Taishan Night Market from the following angles.

\subsection{Strengthen the Management of Night Market Outlets and Solve Infrastructure Problems}

The basic problem of Taishan Night Market reflected in the present situation of food and clothing is that the night market led to the road operation affects traffic, food hygiene difficult to be guaranteed, noise, garbage, oil fume and so on.

In view of the present situation, it is necessary to strengthen the night market 
basic environmental hygiene management first from the organizational structure. The organization and management methods of Taishan Night Market are composed of three parts: government intervention management, market management office coordination and night market operators spontaneous organization and supervision, which promote the development of night market. This development mode proceeded from multiple subjects. The three parties manage and supervise each other, which can better supplement the shortcomings of a single subject.

From the official point of view, in 2011, Tai'an law enforcement officials have carried out a reasonable regulation of vendors, issued "Tai' an Catering Service Food Procurement Requesting Ticket Ledger", reasonably guided the development of the night market, regulated the sanitary conditions and pollution of the night market as far as possible, strengthened infrastructure construction, and avoided the original problems on the basis of ensuring the basic functions of the night market. However, in the actual implementation process, the night market is still often complained by local residents because of the excess and strong mobility of the stalls in the night markets, the unilateral control effect is limited, so on the basis of government's policies and strengthening law enforcement efforts, it should also be managed through the self-restraint of the market and industry. For example, fixed vendors set up the self-discipline management organization of Taishan Night Market and spontaneously form a series of regulations. Although this method mainly depends on the voluntary compliance of vendors, the basic management environment of the night market will be greatly improved on the basis of environmental constraints and the improvement of each vendor's consciousness. Some of the less self-conscious vendors will also change due to the overall changes in the environment, as an auxiliary institution for night market management, the existence of industrial self-regulatory management organization will assist the government to complete the night market management strongly.

The problem that the local fixed network cannot meet the needs of the residents needs to be solved by strengthening the infrastructure construction and increasing the number of outlets. Taishan Night Market is located at the intersection of three main roads, which has enough space to build a commercial street. It is necessary to set up a certain number of commercial outlets in the blocks through the Taishan Night Market to carry out the pilot, to distinguish between fixed vendors and mobile vendors, and to move into some of the original merchants of Taishan Night Market as fixed merchants, which are mainly characterized by catering and entertainment outlets, in an attempt to gradually build a night-time commercial street. Introducing basic shopping and food outlets into the streets and providing vendors with a fixed sales location can not only solve the problem of insufficient demand, but also solve the problem of night occupation in time, and the fixed commodity outlets are also easier for the government to manage. 


\subsection{Building Network Information Platform and Innovating Management Mode}

The night market vendors are divided into long-term and short-term, long-term vendors can go to the night market management office for long-term rental procedures with identity cards, business licenses and other valid documents, night market management office is responsible for qualification examination and booth distribution; short-term vendors can apply for the right to use a short-term booth which is daily fees and may not lease for more than 15 days through a government-led network information platform or mobile phone APP to certificate online real name and exam qualification. Long-term and short-term vendors are separated on both sides of the night market road, short-term vendors mainly arranged along the street with shops on one side, shop operators can also participate in the management of rental stalls.

The construction of a network platform can integrate night market related information efficiently and form a systematic and complete network information circle. Meanwhile, it is effective to promote the network and information development of night markets. It reduces investment costs and expands the night market propaganda area, and attracts more potential operators, especially young groups such as college students, and adds new vitality to the night market. It improves the utilization efficiency of night market space to achieve maximum and optimal utilization.

At the same time, the management of night market operators is not only the work of the government, but also the participation of other subjects in management, so management rights should be liberalized, and cooperation among store operators should be strengthened. Each store operator has the right to manage the stalls in front of the store, and has the right to determine the daily rental time and duration, and share the information on the network platform or mobile software. After the night market management office or the network information platform collects the booth fee, it will be paid to the corresponding store operator according to a certain proportion, and the shop operators must be responsible for the garbage cleaning and sanitation maintenance in front of the door, otherwise the corresponding booth fee cannot be obtained.

In this way, the efficiency of night market management is improved, and the management enthusiasm of operators is stimulated. Shop operators get extra income in this management mode, and then actively assume responsibility and improve the overall management efficiency. The government management assisted by multiple parties of the night market lightens the work burden, and maintains the environmental hygiene of the night market, which is the perfect embodiment of the win-win cooperation between the government and the vendors.

\subsection{Create Intensive Cultural Management Characteristics and Combine Taishan Culture with the Transformation and Development of Night Markets}

The value of night market cannot be actually reflected without the integration of 
night market and characteristic culture. Before excavating the characteristics of the night market, we first need to have a sufficient understanding of Taishan culture. Tai'an has a long history which has been recorded as early as five thousand years ago, Du Fu's poem "When shall I reach the top and hold, all mountains in a single glance" added ancient rhyme for the magnificent Mount Tai. As a national 4A-level scenic spot, Mount Tai is majestic and has a wealth of products. The "Three Beauty of Mount Tai" and the "Daughter Tea of Mount Tai" are all well-known specialty products of Tai'an; the religious Buddhist temple Puzhao Temple and Taoist temple Guanbixia Temple also famous, from ancient times, many emperors have held the Fengshan Ceremony on Mount Tai, The "national mountain" culture with the dominance of the Five Sacred Mountains, the peace of the country, and the happiness of the people endows Mount Tai with strong traditional and political colors, there are also many folks who say "climb to Mount Tai to ensure safety", which is an irreplaceable cultural belief of the Chinese people and a cultural symbol of the Chinese nation; This kind of culture develops to the modern, has also derived ideas like the spirit of Mount Tai heavers and so on, endowing new cultural connotation to Mount Tai. In any era, Mount Tai occupies an extremely important position in Chinese culture. Based on this cultural background, we should reconstruct the night market from the perspective of characteristic food, products and cultural activities.

With the continuous upgrading of consumer demand and consumption levels, people hope to obtain comprehensive services at the same or similar locations efficiently, so the concept of intensive management has emerged. This concept has been practiced and achieved good results in cities. Taishan Night Market can also create cultural intensive management to reflect the cultural connotation of Mount Tai, and increase the products and activities related to Taishan culture to the organization of night markets.

Therefore, this paper proposes the following methods to solve the current development dilemma of Taishan Night Market.

Firstly, increase the sales booths of Tai' an characteristic food and characteristic products, selling some products such as "Three Treasures of Mount Tai", "Three Beauty of Mount Tai", "Taishan Stone Carvings" and so on, and inject cultural connotation into the sales process, combined with local myths and legends, traditional stories of Tai'an, add deeper meaning to food and products, increase the added value of products. Tourists or residents not only consume characteristic products, but also cultural sentiments and Mount Tai sentiments.

Secondly, for the propaganda of folk culture, increase investment in Taishan folk drama club, develop the traditional folklore projects such as Taishan shadow puppetry and competitive arena, which are gradually forgotten in modern society, interact with tourists or hold special exhibitions. These methods also ensure the development and inheritance of folk treasures like intangible cultural heritage to some extent.

Finally, organize large-scale activities to commemorate traditional festivals, such as Lantern Festival Ceremony and "Fengshan Ceremony", such activities 
can become an important publicity point of Taishan Night Market and increase popularity; theatrical performances such as "BaoEn Celebration" in the Relics Park of Dabaoen Temple in Nanjing, "Impression of the Liu Sanjie" in Guilin, Guangxi, and "Jinshanfoyu" in Zhaoyuan, adopted similar methods and performed live performances based on local cultural heritage. These performances allow the audience to experience the traces of history through the land where the ancients have walked during the tour, which can also generate cultural and spiritual resonance. Mount Tai has unique advantages as a heritage of Chinese culture.

China's confidence is also the confidence of the ancient culture. Through the intensive management of culture, the combination of characteristic food, products and activities can generally promote the core attraction of Tai'an and stimulate domestic demand and external demand. Externally, the Taishan culture is the business card of the Taishan Night Market, allowing tourists to remember the Taishan Night Market and understand the Taishan culture; internally, it allows the people of Tai'an and even Shandong to have a deeper understanding of their own cultural accumulation, enhance cultural confidence, and let the development of the night market feed back the development of Taishan culture and achieve a win-win situation.

\subsection{Cultural Development Combined with the Concept of "Sharing" Economy to Create Greater Benefits}

The reason of problems such as interest friction caused by individual space game in Taishan Night Market, management omissions caused by limited urban governance capabilities, spread of secular customs and weakening of cultural concepts, etc. is a slack in management and control on the one hand, but most importantly, it is the local government who lacks understanding and thinking of night market culture and night market culture management. If we only cater to the economic income in the process of development and ignore the development of night market culture, it will inevitably lead to the malformation of night market development; but if we put too much emphasis on the cultural connotation and avoid discussing economic development, it may cause too much investment in the night market, less revenue, and unable to maintain basic operations. Therefore, finding a balance between cultural development and economic development is also a problem for managers to consider.

The Fifth Plenary session of the 18th CPC Central Committee put forward the idea of "developing the sharing economy", which has become an important direction of national economic transformation. As a new type of economic model, the sharing economy has improved the utilization and efficiency of resources and its rational use has already achieved initial results in many industries, and the concept of using the sharing economy has also become an unstoppable economic development trend; at the same time, "Culture Sharing" is a new type of cultural construction project of the important thinking of the "Three Represents". Their existence can provide a new direction for the development of the night 
market. In the place like the night market that has a strong "sharing" function and "sharing" potential, combining cultural characteristics and sharing ideas will bring about a leap in benefits and results.

Relevant departments can carry out rectification and reform based on the requirements of the policy and the status quo of the night market combined with the concept of "sharing economy" to create a "sharing night market."

The model of "shared night market" expands the choice space and welfare promotion space of trading subjects, changes people's concept of property rights, and changes the operating environment of traditional industries, uses the model of $\mathrm{C} 2 \mathrm{C}$ open platform and Airbnb to share the space of night market, and shares the power of night market management in accordance with the decentralization policy, provides convenience for tourists and consumers, and creates shared infrastructure, etc., in order to conform to the development trend of sharing and promote the sustainable development of night markets.

The combination of economy and culture is bound to bring new development opportunities to Taishan Night Market, but at the same time, Taishan Night Market also needs to undergo fundamental changes.

First of all, guide operators to carry out cultural-related business activities, and actively support operators who have already operated cultural commodities in the night market, help them develop and promote their transformation, and increase the number and scope of operators who accumulate cultural product from the perspective of operators;

At the same time, make reasonable use of network resources and share network information platforms. Effectively promote and popularize the Taishan culture and the present situation of the night market, realize information sharing, integrate the resources of the night market efficiently, improve the overall management, scheduling and propaganda level, and open a window for the outside world to understand the night market;

Second, share night market space and infrastructure. The operation needs of the site and related infrastructure can be uniformly allocated by the government and reused, shared stalls, jointly maintain the integrity of the infrastructure, if there is damage or loss, the two sides shall jointly bear the corresponding responsibility, reasonably allocate the infrastructure according to the size of the passenger flow. The sharing of infrastructure is beneficial to the rational and efficient use of resources, and improves and improves the efficiency of infrastructure utilization, which is of positive significance to the integrity of infrastructure. The mutual supervision of night market vendors and shop operators will also effectively avoid the wear and loss of infrastructure during the use process. Through the sharing of infrastructure, the competition between vendors and shops has been strengthened, which has a great effect in promoting the economic development of the night market and is conducive to the further development of the night market.

Finally, we should pay more attention to the related cultural activities and realize "cultural sharing". "Cultural sharing" is a new type of cultural construc- 
tion project that carries out the important thought of "Three Represents". Popularize night market culture and Taishan culture, increase the publicity of civilization. The relevant departments can set up activities with Taishan culture in the appropriate areas, actively support the operators of cultural commodities in the night market in accordance with the actual situation of the night market or the needs of foreign tourists, so that everyone can share cultural resources. Let the night market show the unique way of life of Tai'an citizens, so that make the culture internalize in the heart, externalize in the form. Break the limitation of space, combine the management activities with the special activities like literary and artistic exhibitions, reduce the occupation of the overall space of the night market and the use of resources, and realize the rational and efficient use of resources.

Culture and economy permeate and influence each other. Although the development of the night market, the preparation of infrastructure and the investment in cultural propaganda require economic input from the government, the potential benefits are immeasurable. In addition, with the support of the "sharing economy", it can save more resources and costs and gain greater benefits. This kind of benefit is not only economic benefit, but also social benefit and cultural value.

\section{People's Livelihood Benefits of Taishan Night Market Transformation}

As a special economic model, night market is a good extension of daytime economic activities. If it can be integrated into cultural characteristics, it will create economic vitality, increase entrepreneurial opportunities, prolong the consumption time of consumers, and bring great benefits.

A "new night market" that meets the needs of modernization should take the economic function as the core, take into account the interests of traders, consumers, residents, tourists, managers and so on, realize the true sense of "win-win situation", and work together to transform the night market, rather than simply ban or abolish it. We explore the way out of Taishan Night Market, not only hope to seek a model for the night market to maintain its own business, but also hope that such a special business model can pull its own development in a virtuous circle, stimulate its own development through self-improvement, and become a new growth point. Run through the concept of culture in the transformation of the night market, and create a new characteristic cultural window of Tai'an, so that Taishan Night Market can have both a clean and tidy environment, and an efficient management model, meanwhile becoming a place containing a deep cultural heritage.

From the perspective of residents, the night market is a place for residents to relax, enrich their lives and provide more convenience. In terms of the value of tourism, the night market, as a city business card, can attract a large number of tourists to visit, bring economic benefits, and promote the construction of the 
night market, better playing its function. For the society, most of the mobile vendors in the night market are laid-off workers and the unemployed; this part of vendors is more difficult in life, the existence of the night market gives them employment opportunities with more flexibility and low entry barriers, ensures their basic living needs, alleviates employment pressure, and provides an open and competitive employment environment, encourages entrepreneurship and molds a good social atmosphere ... From all levels, it is necessary for Tai'an to develop the Taishan Night Market.

At present, Taishan Night Market still has the problem of further transformation and improvement. How to make the night market take into account economic function, cultural function and social function is an important proposition at present. We hope that on the basis of improving the basic management level, Taishan Night Market can strengthen the indoctrination of characteristic culture of the Mount Tai, enhance local cultural pride, attract more consumer groups, give play to the subjective initiative of different subjects, stimulate domestic demand, promote overall development, and jointly achieve the prosperity of the night market.

\section{Funding}

This work is supported by Social Science Project of Taian (20-YB-001).

\section{Conflicts of Interest}

The authors declare no conflicts of interest regarding the publication of this paper.

\section{References}

Jiang, Y., Kellard, N., \& Liu, X. (2020). Night Trading and Market Quality: Evidence from Chinese and US Precious Metal Futures Markets. Journal of Futures Markets, 40, 1486-1507. https://doi.org/10.1002/fut.22147

Li, X., Kong, W., \& Yang, F. (2021). Authentic Food Experiences Bring Us Back to the Past: An Investigation of a Local Food Night Market. Journal of Travel \& Tourism Marketing, 38, 233-246. https://doi.org/10.1080/10548408.2021.1902910

Liu, C., Chou, S., \& Lin, J. (2021). Implementation and Evaluation of Tourism Industry: Evidentiary Case Study of Night Market Development in Taiwan. Evaluation and Program Planning. (In Press) https://doi.org/10.1016/j.evalprogplan.2021.101961

Villaseca, M. R. (2021). Urban Metabolism of ASEAN Night Markets Based on Biological Principles. City and Environment Interactions, 9, Article ID: 100055.

https://doi.org/10.1016/j.cacint.2020.100055 